\title{
MOEDAS DA POESIA EM GASTÃO CRUZ
}

\author{
Sandro ORNELLAS (UFBA) ${ }^{1}$
}

RESUMO: A partir da leitura da antologia A moeda do tempo e outros poemas, do poeta português Gastão Cruz, enceta-se uma reflexão sobre a memória da própria poesia presente no seu discurso e no seu texto. Para isso, toma-se a sua metáfora da moeda para balizar leituras de uma tradição lírica clássica e de uma tradição lírica moderna como valores trabalhados pela memória da poesia de Gastão. Pretende-se dessa forma sugerir uma reflexão mais ampla sobre a memória e a tradição lírica na poesia contemporânea e sua historicidade.

PALAVRAS-CHAVE: Poesia portuguesa contemporânea; Memória e tradição lírica; Poesia e historicidade; Poesia 61; Gastão Cruz.

ABSTRACT: As of the reading of the anthology A moeda do tempo e outros poemas, of the Portuguese poet Gastão Cruz, it is began a reflection on the memory of the poetry itself, present in his speech and his text. In order to accomplish such reflection, his coin metaphor is the ground to indicate readings of a classical lyrical tradition and of a modern lyrical tradition as values elaborated by Gastão's poetry memory. Thus, it is intended to suggest a wider reflection over the memory and over the lyrical tradition in the contemporaneous poetry and its historicity.

KEYWORDS: Contemporaneous Portuguese poetry; Memory and lyrical tradition; Poetry and historicity; Poesia 61; Gastão Cruz.

A moeda do tempo e outros poemas, do poeta português Gastão Cruz, é uma antologia que acerta dois alvos com um só golpe. Antologia pedagógica que apresenta poemas exemplares de todos os livros do poeta e, simultaneamente, que consegue mostrar a face coerente da sua obra, de mais de duas dezenas de títulos e quase cinqüienta anos de produção ininterrupta. Pertencente ao grupo de poetas portugueses que em 1961 se lançou no mundo da poesia portuguesa com a publicação coletiva denominada Poesia 61, Gastão Cruz é o último dos cinco jovens poetas de então (ele mais Luiza Neto Jorge, Fiama Hasse Pais Brandão, Casimiro de Brito e Maria Teresa Horta) a ser lançado no Brasil. Fiama foi através de uma antologia anexada a um livro de ensaios - Lápide \& versão (2006) - a ela dedicados e escritos pelo professor titular da UFRJ, Jorge Fernandes da Silveira, também responsável pela organização desse $A$ moeda do tempo e outros poemas. A antologia foi recém-lançada pela Língua Geral, em 
edição belissimamente cuidada, composta de bibliografia ativa e passiva do poeta, da "Apresentação" de Luis Maffei e "Orelha" de Maurício Matos.

Os poetas de Poesia 61 notalibizaram-se por desviarem os rumos da poesia portuguesa de então, presa demasiadamente aos esquemas psicologizantes da poesia do grupo de Presença e seu influxo pessoano e aos comprometimentos sociologizantes da poesia neo-realista e seu influxo marxista sob o espectro da ditadura fascista (havia ainda o surrealismo e autores independentes como Eugênio de Andrade, Sophia de Mello Breyner Andresen, Jorge de Sena e Antonio Ramos Rosa). Contemporâneos ao estruturalismo teórico-crítico, seus jovens poetas levarão ao cenário poético português uma concepção topológica de poesia, ou seja, o texto como o lugar onde o sentido efetivamente se produz, não em uma subjetividade anterior ou exterior a ele, pertencente ao mundo social. Essa tipologia (psicológica, sociológica e topológica) da contribuição da Poesia 61, aliás, é do crítico Eduardo Prado Coelho (1972b, p. 265), falecido em 2007 e contemporâneo dos poetas. Ele (junto com o brasileiro Jorge Fernandes da Silveira, que publicou em Portugal, em 1986, sua tese intitulada Portugal Maio de Poesia 61, ainda inédita no Brasil) foi um dos grandes sistematizadores das contribuições dos escritores dessa geração, que faria história e renovaria o panorama poético português, tão afeito na época a radicalizações políticas: lembremos de passagem que era o momento de deflagração da guerra contra a independência das colônias africanas. A Poesia 61 mostrava aos poucos que para o poeta a politização sempre foi feita no espaço do texto, por suas escolhas e codificações. O poeta e crítico Luis Miguel Nava (2004, p. 195-6) afirmará mesmo que havia um "quê de laboratorial e de pesquisa nos limites do dizível", o que parece absolutamente correto do ponto de vista de experimentos na sintaxe sobretudo, com uma escrita "onde a elipse assume papel soberano [e] o sentido é de certo modo diferido". Mas, ainda assim, a Poesia 61 mantinha-se relativamente diversa de outros contemporâneos seus, que também reconfigurarão o cenário da produção poética portuguesa. Exemplarmente, o lançamento da poesia cósmica de Herberto Helder, da poesia de longo fôlego discursivo de Ruy Belo e as filiais d'além-mar da invenção concreta, com Ana Hatherly e E. M. de Melo e Castro. Dos cinco poetas dePoesia 61, Luiza teve a performance mais fulgurante e desapareceu em 1989, Fiama faleceu em 2007, depois de produzir uma obra de 
qualidade excepcional. Os demais continuam produzindo e são hoje figuras tutelares da poesia e da literatura em Portugal.

\section{A moeda clássica}

A poesia de Gastão Cruz é discreta, e nisso talvez possa soar com uma certa feição clássica para alguns leitores, pela sua "gravidade" (NAVA, 2004, p.197) discursiva e serenidade afetiva, misturadas em uma poesia meditativa e intelectualizada. Vemos isso já em 1965, quando Gastão - no livro Outro nome, sem qualquer vontade paródica, apenas o mais discreto gesto de interlocução discursiva entre línguas poéticas distantes no tempo - relê Camões, obviamente como a moeda maior nesse sistema de trocas que é a memória da poesia. No início da "Canção quarta", lemos esse gesto de interlocução, que não se faz simples diálogo reverente ou epigonismo meramente técnico: "Outro nome canção hoje daremos/ ao dia luminoso que nos cobre/ com a pedra e a cinza endurecida/ desertos dias morte/ e outro nome/ [...]" (2009, p. 153). Muitos anos depois, em Crateras, de 2000, o poema "Erros" torna explícita a interlocução com o Camões de "Erros meus, má fortuna e amor ardente", ao escrever:

Não sei se má fortuna erros decerto erros somente? Pode o amor ardente, algum tempo omitido, descoberto cobrir de novo a pele neste presente,

que de pouco já serve a sua chama lugar comum tão pobre e tão verídico $[\ldots]$

(CRUZ, 2004, p. 74)

Interlocução que se faz classicamente discreta, por agudezas semânticas habilmente dispostas entre "descoberto" e "cobrir", formando um engenhoso quiasma entre os versos. Ao mesmo tempo, a pobreza do "lugar-comum" como tópica amorosa no "presente" produz uma ironia com os "erros" de Camões, que Gastão diz 
compartilhar; "erros" que tornam o famoso Eros camoniano "pobre" - de locus communis clássico em "lugar-comum" moderno.

Essa moeda clássica de Gastão pode talvez ser encontrada ainda em certo gesto trágico diante da vida e da própria linguagem poética. Quando a fatalidade da vida e da morte - às vezes encharcados com o travo do amor - tem como elemento de sobriedade a linguagem; lê-se: "Mora no corpo ainda a errante/ linguagem?/ A língua do abismo/ só os olhos a falam" (2009, p. 65, "Vidro"), ou então: "Eu podia já ter/ morrido e seria/ apenas uma imagem que morria/ como tu suicida nesse quarto/ de mil novecentos e sessenta e quatro// imagem para mim eterna todavia,/ a minha eternidade é a minha vida/ e tudo o que existir para além da memória/ que guarda a imagem transitória// já não será o corpo onde tu estarás/ porque ele mesmo há-de tornar-se abstracto" (2009, p. 33, "A minha eternidade é a minha vida"). Como não reler nesses versos o Camões (indicado por Jorge da Silveira no posfácio a Gastão) de "E aqueles, que por obras valerosas/ Se vão da lei da Morte libertando./ Cantando espalharei por toda parte,/ Se a tanto me ajudar o engenho e arte" (I: 2), na proposição do seu épico?

$\mathrm{Na}$ verdade, sublinhada por vários de seus comentadores, desde Eduardo Prado Coelho em seus artigos analíticos até os comentadores contidos na antologia, a mudançapara Gastão - que se apresenta na tópica clássica do desconcerto, assim como em outras tópicas como o tempus fugit e a incontornabilidade da morte apresenta-se como seu tema por excelência. A percepção da inexorabilidade do tempo e da mudança que traz se faz na poesia clássica como forma de conteúdo(para usar uma expressão do lingüista Louis Hjelmslev) condensada em diversos lugares-comuns. Gastão, leitor atentíssimo de poesia, guarda a memória dessa percepção, tão cara à poesia clássica. Mais precisamente, ele guarda a memória dessa poesia, sem precisar para isso saturar seus textos de referências clássicas através de uma linguagem academizante, tão afim a certos poetas contemporâneos - brasileiros e portugueses que fazem profissão de fé do anacronismo, a exemplo de Bruno Tolentino, no Brasil, e de Vasco Graça Moura, em Portugal. O classicismo de Gastão é, à maneira de Nietzsche, intempestivo, pois não investe contra o presente (em nome de improváveis "valores eternos"), mas compõe com ele um bloco de forças que impulsiona a vida para frente, jamais para trás ou para fora da história. 
A discrição da poesia de Gastão muito provavelmente é o que faz seu texto ser considerado hermético. Discrição essa que faz as vezes de ética da linguagem, também presente na declaração de princípios do poema inicial e homônimo de seu último livro, A moeda do tempo, de 2006, em que ainda podemos encontrar uma espécie de ética epigramática clássica: "Distraí-me e já tu ali não estavas/ vendeste ao tempo a glória do início/ e na mão recebeste a moeda fria/ com que o tempo pagou a tua entrada" (2009, p.31). Aí a recusa à mercantilização da vida faz par com a constatação da passagem do tempo pela tópica (tão camoniana) do desconcerto ("Distraí-me e já tu ali não estavas"). Na "distração" de conseqüências discretamente recusadas, a moeda forte que abre (e marca) a posição do poeta perante a mudança.

Mas a percepção dessa passagem do tempo - que os neoclássicos contemporâneos tanto recusam - também implica num "encontro de tempos", tão próprio da poesia moderna, em que a temporalidade histórica do nível “discursivo situa o nome e o modaliza" (BOSI, 2000, p. 135, grifos no original) junto aos elementos mais imanentes e menos históricos do texto (gêneros, formas, metros, ritmos, cadências, rimas, etc.).

\section{A moeda moderna}

Apesar das aparências, do influxo verbal e da argumentação acima disposta, a poesia de Gastão está longe de ter feição fortemente clássica. Isso porque ela opera com um discurso poético cuja linguagem parte, sobretudo, de uma matriz moderna, numa espécie de "encontro dos tempos", conforme exposto anteriormente; aliás, da mais radicalmente moderna de todas as poesias modernas. Se possui, a poesia de Gastão, uma solenidade por vezes inquietante a um leitor de poesia moderna brasileira e sua entoação sintática entre o coloquial e o agressivamente anti-discursivo e descontínuo, a poesia do português na verdade flui diretamente das linhagens poéticas do final do século XIX e de início do século XX. Quero dizer, do Mallarmé de "Cemitério marinho", "O azul" e de sonetos como Salut etambém das poéticas modernas e portuguesíssimas, como foram a de Camilo Pessanha e Fernando Pessoa. Todas - cada uma à sua maneira cadenciadas, impostadas e solenes. 
Se cito Mallarmé é porque compartilho da idéia de Luis Miguel Nava (2004, p. 192) de que

[...] para o entendimento da restante poesia portuguesa do século XX [referese ao modernismo e à poesia posterior a ele], é indispensável não só encarála como um todo, de forma a entre os vários poetas detectar os nexos existentes, mas também entrar em linha de conta com as marcas que, em sucessivas levas, nela têm deixado poetas de outras línguas.

A consciência da linguagem de Gastão, que foi o principal crítico, ainda nos anos 1960, da geração a que pertenceu - e que tem no livro A vida da poesia (Lisboa, Assírio \& Alvim, 2008) sua reunião de intervenções e reflexões críticas -, é moderníssima naquilo que ela tem de estranhamento sintático e de uso lexical levado ao extremo da produção de sentido (o De la musique avant toute chose verlaineano e, principalmente, o mot juste do próprio Mallarmé), como em "Desse espelho molhado colhe o brilho/ como as folhas de julho alheio à/ velocidade da vida" (CRUZ, 2009, p. 109, "Rios"); ou em "A cor da carne/ à noite/ nos intervalos da água// Porque o vento é aberto/ é que nos sabe a branco nos ouvidos" (CRUZ, 2009, p. 175, sem título), do primeiro livro de 1961, A morte percusiva, com Gastão aos 20 anos. Não é o Mallarmé de Un coup de Dès que tanto estilhaçou a poesia, como está evidente, mas o Mallarmé ontológico e negativo de aboli bibelot d'inanité sonore e de Je ne viens pas ce soir vaincre ton corps, ô bête.

Se a emoção intelectualizada do francês é guardada em versos como "Num tempo neutro acordo/ entre a noite e o dia/ sob um céu ilegítimo condensa-se/ a mudança/ Nuvens totais exprimem/ a presente longínqua/ madrugada/ as aves sobrevivem na queda/ ao/ tempo branco" (CRUZ, 2009, p. 115, “Transe”), a ontologia ganha um pouco mais de positividade (não demais, é claro...) e de corpo no sujeito que - se em Mallarmé é elidido - em Gastão volta como perspectiva. Note-se que o frio e impessoal "bibelô" se torna mundo perspectivado pelos sujeitos em versos como "O mundo acabará quando não formos nós/ o mundo: tudo existe/ somente no olhar" (CRUZ, 2009, p.39, "Nós o mundo") ou em "Aprendi a clareza das imagens fictícias/ recolhidas na luz do corpo nu e vivo" (CRUZ, 2009, p. 125, “A vida da poesia”). Aliás, 
este poema merece ser lido inteiro por mostrar o acréscimo do corpo e da positividade à pura negatividade de Mallarmé:

Hoje sei como se exprime a vida da poesia com a sinceridade das emoções lingüísticas com que o mundo devasta e enche as nossas vidas

Aprendi a clareza das imagens fictícias recolhidas na luz do corpo nu e vivo entre os golpes orais, errantes, desferidos.

(CRUZ, 2009, p. 125)

A poética do fingimento e a do testemunho nunca me pareceram se opor. Fernando Pessoa minou sua poética do fingimento com afirmações paradoxais que retornam no mesmo instante em que vão, o que faz dela uma forma absolutamente oblíqua (como a chuva do seu poema) de dizer de si testemunhalmente. Daí que Gastão Cruz usa desse fingimento testemunhal e dessa "sinceridade linguística" como contrabalança à ontologia negativa de Mallarmé. O corpo é presença constante em seus poemas. Não o corpo-máquina-convulsiva-de-Artaud e de outros modernistas dentre os quais o Campos do próprio Pessoa -, mas o corpo da própria poesia, da experiência direta e viva com a forma, que no francês beira o inefável, enquanto em Gastão

Tem vários fins a vida e quando começa já não lhe dá o corpo a mesma pressa

Tão depressa se esconde numa curva sem luz como atravessa a estrada procurando a outra berma

Tem sucessivos fins e todos verdadeiros É sempre 
o mesmo corpo o mesmo o nevoeiro.

$$
\text { (2009, p. 73, “Sem luz”) }
$$

As moedas modernas da poesia de Gastão Cruz são poucas, constantes e precisas, mas ele não as vende ao tempo. Lega-as ao esquecimento e à lembrança da poesia futura, como deve ser em toda poesia forte, já que são os poetas os mais autorizados detentores da memória da poesia, são os poetas os reais leitores (quiçá os únicos) de poesia. Essas moedas fazem as vezes de formas, como de léxico e de entonação. Ao mesmo tempo, elas também provêm das reservas pessoais de Gastão. Um soneto publicado ainda jovem, em Hematoma, de 1961, revelava um poeta com vinte anos que dava um banho de sabedoria poética e política em muito poeta mestre da esquerda empedernida e sem sensibilidade poética, e isso através de um soneto, não do verso livre. Abre esse soneto a estrofe primorosa: "Um verso é uma zona proibida/ zero prego tabu o sol nos dentes/ a zona é uma voz intrometida/ as pessoas são vozes doentes" (2009, p. 169, sem título), que aponta para o trabalho político do poema em ser a "voz intrometida" entre "dentes" e "doentes" (que formam mais do que uma hábil rima, mas um par praticamente homófono, embora semanticamente oposto) em uma época de censuras e proibições fascistas em Portugal. Na imagem do segundo verso, "zero prego tabu o sol nos dentes", um decassílabo cujo andamento acidentalmente recria a atmosfera de confronto, quando de um lado há o ritmo alternado de forte/ fraca/ forte/ fraca em "zero prego" que muda para fraca/ forte/ fraca/ forte/ fraca/ forte em "tabu o sol nos dentes", muito exatamente no "tabu", que funciona no verso como barra de separação e virada no andamento e, é claro, no sentido.

O trabalho político é trabalho poético, pois o trabalho do poeta afirma, no início do segundo quarteto, que "Também do chão ascendeu o ciclista". Esse verso dialoga com o verso do seu contemporâneo, Herberto Helder (1990, p. 295), que escreveu "Lá vai a bicicleta do poeta em direção/ ao símbolo". Ou seja, é o que Eduardo Prado Coelho (1972a, p. 227), que lhe dedicou uma série de quatro artigos críticos recolhidos em $O$ reino flutuante, de 1972, diz: “a poesia de Gastão Cruz é, pois, em grande parte, um jogo de símbolos muito complexo e realizado em diversos níveis. Sem dúvida, isso 
pode contribuir para que ela seja demasiado abstracta e aparentemente fria". Esse argumento de Prado Coelho reforça o limite da memória mallarmaica de Gastão Cruz, assim como o desenvolvimento do argumento amplia esses limites também para a poesia de Pessoa, repleta de simbologias mítico-esotéricas:

[...] essas metáforas-símbolos são sempre obtidas segundo um mesmo processo: encontramos sempre termos concretos a significarem realidades abstractas. Todo o processo metafórico em Gastão Cruz parte de uma base materialista. É por isso que a profusão de símbolos não conduz a uma poesia mítica (1972a, p. 227).

Daí nos vem novamente Herberto Helder (1990, p. 295), que diz ainda no mesmo poema: "O símbolo é simples". É o que Gastão opta por fazer no penúltimo verso: “as árvores as árvores as árvores" (2009, p. 169): “a poesia de Gastão Cruz, portanto, caracteriza-se pela repetição. (...) a repetição não altera só o conteúdo conceptual dos símbolos: altera, ainda, o seu valor afectivo" (COELHO, 1972a, p. 227).

\section{Memória da poesia}

É comum hoje se afirmar que a poesia é lida - sobretudo, se não exclusivamente - pelos próprios poetas. Que seja assim, isso só justifica a assertiva de que são os próprios poetas que guardam a memória da poesia que eles produzem. A sua história é formada por inúmeras e diversificadas linhagens, tradições e trilhas, às quais os poetas se filiam ou recusam, a depender de como lêem os poetas que lêem. E o lugar para se conhecer os poetas e os poemas que os poetas lêem (os reescrevendo) não é nas suas entrevistas, diários ou aventuras críticas, mas nos seus poemas. É nos poemas que está a memória da própria poesia, é neles que se guarda, se revisita e se reelabora palavras, versos, metros, ritmos, formas, gêneros, signos, imagens canônicas ou marginais à história - pouco importa. É por meio dessas operações de escrita-e-leitura que os poetas se agrupam em famílias coerentes ou contraditórias, harmoniosas ou tensas. A poesia se faz, assim, um lugar privilegiado para se estudar a história e a memória cultural.

Sobre essa memória, assim como ler é reescrever o lido, escrever é ler o escrito. É o que - sobre as categorias de leitura e escritura que dominam salas de aula desde aproximadamente os anos 1960 - asseveram diversas teorias. Escrever a própria poesia, 
então, seria ler a poesia alheia do passado recente e distante, ler obliquamente, levado pelo desafio (da emulação, da laudatória, da paródia, do pastiche, do diálogo e do intertexto) e pela imaginação. Arte e engenho. E ler a poesia alheia do passado recente e distante seria ler uma poderosa máquina de inscrição da memória cultural moderna: nações, raças, sexualidades, afecções diversas são tópicos permanentes da tradição lírica, aos quais são somados outros, próprios de cada tempo. Ler a poesia alheia e passada também seria ler os suportes mesmos de impressão dessa memória poética: os corpos - individuais, históricos, políticos, poéticos - que os sujeitos vestem com seus discursos. Escrever poesia, portanto, seria discutir esses corpos, submetê-los à leitura alheia (presente e futura), entre o canto público do épico e a experiência privadamente fingida do lírico, entre a tradição trágica e a tradução dramática, entre o eu e o outro esses, alguns nós da poesia no espaço curvo da história. Se a poesia lírica portuguesa pode ser entendida como uma escrita e um saber de si, é porque ela justamente se dobra no espaço público do mesmo (Camões) como uma escrita e um saber do outro (Pessoa).

É assim, então, que Gastão Cruz transita no espaço - ínfimo na sociedade contemporânea, mas gigantesco na memória - da sua poesia:

[...] a poesia por seus constritores inerentes (artesanais e tecnológicos) praticamente não se altera. É, pois, pobre. Não se alterou a poesia desde suas primeiras formulações conhecidas como tal. Seu tempo é de longuíssima duração. Quanto mais restritiva é uma estrutura, mais incapaz de modificarse. Maior permanência, logo. Sobrevive em função da sua miséria (SANTOS, 1998, p 48).

Nesse trânsito pela memória, que a poesia de Gastão executa, acumulam-se signos e imagens que sobrevivem às agruras dos tempos e se encontram na pouca variabilidade, muita repetição e, assim, "pobreza". Pobreza típica de toda poesia que tem seus rompantes condensados nos mesmos gestos da memória psíquica freudiana: repetir, recordar e elaborar. A memória como sistema de trocas simbólicas que vê na poesia uma moeda de baixa variabilidade (embora elavadíssima precisão) e baixa circulação (embora elavadíssima intensidade). Ela opera à margem dos grandes mercados produtores de bens simbólicos. E isso Gastão e seus companheiros de geração bem o sabiam, pois fizeram "uma poesia pobre" (NAVA, 2004, p. 195), uma poesia de 
recusa às realidades suntuosas compradas com moeda fácil, pois sua moeda é outra e afirma que "assim o poeta:

com o buril inscreve na deserta chapa do mundo não interpretado o sentido precário de o olhar.

(2009, p. 38)

\section{Referências}

BOSI, A. Encontro dos tempos. In: O ser e o tempo da poesia. 5.ed. São Paulo: Companhia das Letras, 2000. p.130-62.

COELHO, E. P. Gastão Cruz: doença, mudança e incêndio. In: flutuante. Lisboa: Edições 70, 1972a. p. 225-32. O reino Apresentação de um livro: “(Este) Rosto”. In: . A palavra sobre a palavra. Porto: Portucalense, 1972b. p. 263-72.

CRUZ, G. A moeda do tempo e outros poemas. Rio de Janeiro: Língua Geral, 2009. HELDER, H. Poesia toda. Lisboa: Assírio e Alvim, 1990.

NAVA, L. M. Os poetas revelados entre 1960 e 1990. In: Ensaios reunidos. Lisboa: Assírio e Alvim, 2004. p. 191-209.

SANTOS, R. C. dos. Poesia e esquemas mentais. In: PEDROSA, C.; MATOS, C.; NASCIMENTO, E. (Org.). Poesia hoje. Niterói, RJ: EDUFF, 1998. p. 47-52.

SILVEIRA, J. F. da. Portugal, maio de Poesia 61. Lisboa: Imprensa Nacional-Casa da Moeda, 1986.

SILVEIRA, J. F. da. Lápide \& versão: ensaios sobre Fiama Hasse Pais Brandão, seguido de Memorial de Pedra, antologia. Rio de Janeiro: Bruxedo, 2006.

1 Departamento de Letras Vernáculas - Instituto de Letras da Universidade Federal da Bahia, UFBA, ssornellas@ufba.br 